\title{
The Effect of Overhydration on Mortality and Technique Failure Among Peritoneal Dialysis Patients: A Systematic Review and Meta-Analysis
}

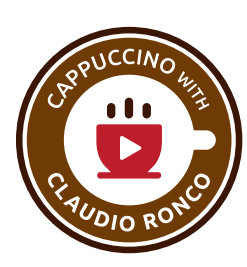

\author{
Ying Shu a,b Jing Liu ${ }^{a}$ Xiaoxi Zeng ${ }^{a, c}$ Hyokyoung G. Hong ${ }^{d}$ Yi Li $^{\mathrm{e}}$ \\ Hui Zhong ${ }^{\text {a }}$ Liang Ma ${ }^{a}$ Ping Fu ${ }^{\mathrm{a}, \mathrm{c}}$ \\ a Division of Nephrology, Kidney Research Institute, West China Hospital, Sichuan University, Chengdu, China; \\ ${ }^{b}$ Division of Nephrology, The Third People's Hospital of Chengdu, Chengdu, China; ' $W e s t$ China Biomedical Big \\ Data Center, Sichuan University, Chengdu, China; ${ }^{\mathrm{d}}$ Michigan State University, East Lansing, MI, USA; ${ }^{\mathrm{C}}$ University of \\ Michigan, Ann Arbor, MI, USA
}

\section{Keywords}

Hydration · Fluid overload · Peritoneal dialysis · Prognosis · Bioelectric impedance

\begin{abstract}
Background: Overhydration is common among peritoneal dialysis (PD) patients and can affect PD-related outcomes. This paper aims to systematically investigate whether bioimpedance-assessed overhydration is a predictor for mortality and technique failure in PD patients. Methods: We conducted a systematic review and meta-analysis of cohort studies on overhydration and prognosis in PD patients, strictly complying with the Preferred Reporting Items for Systematical Reviews and Meta-analyses. Results: Eight articles met the selection criteria and 5 studies were included in the meta-analysis. Meta-analyses-revealed overhydration, defined as a high ratio of extracellular water/total body water (ECW/TBW), was significantly associated with higher risk for all-cause mortality and technique failure. Other higher dichotomized overhydration indicators and continuous hydration variables all indicated overhydration as a significant risk factor for all-cause mortality. Conclu-
\end{abstract}

\section{KARGER}

(c) 2018 S. Karger AG, Basel

E-Mail karger@karger.com

www.karger.com/bpu sion: Overhydration, defined by a higher ratio of ECW/TBW, might be an independent predictor for all-cause mortality and technique failure among PD patients. However, more studies are needed to confirm this conclusion. Video Journal Club 'Cappuccino with Claudio Ronco' at https:// www.karger.com/Journal/ArticleNews/223997?sponsor=52

ㄷ) 2018 S. Karger AG, Basel

\section{Introduction}

Peritoneal dialysis (PD), as a renal replacement therapy, has become popular since its inception more than 2 decades ago. However, PD prevalence remains low because of patient dropouts due to technique failure, such as peritonitis $[1,2]$ or ultrafiltration failure $[3,4]$. In addition, the mortality rate among $\mathrm{PD}$ patients remains high despite the development of advanced dialysis technology. According to the 2014 Annual Data Report from the U.S.

Y.S. and J.L. contributed equally to this work.
Dr. Ping Fu

Division of Nephrology, Kidney Research Institution

West China Hospital of Sichuan University

Chengdu 610041(China)

E-Mail fupinghx@163.com 
Renal Data System, the annual mortality for PD patients was 156.9 per 1,000 patient-years in the United States [5].

Overhydration is common among PD patients, with the prevalence ranging from 56.5 to $73.1 \%$ [6-8]. When considering risk factors for mortality and dialysis inadequacy among PD patients, recent focus has shifted from small-molecule clearance to fluid overload [9]. Fluid overload is considered a contributor to mortality and technique failure among PD patients due to its association with complications such as hypertension [10], heart failure [11], increased cardiovascular event [12], arterial stiffness [13] and peritonitis [14], as well as inflammation [15], malnutrition $[15,16]$ and loss of residual renal function $[17,18]$. However, it remains unclear whether overhydration is an independent predictor of PD clinical outcomes or whether it just reflects underlying comorbidities such as hypertension and cardiac dysfunction.

On the other hand, bioelectrical impedance analysis (BIA) devices, as simple and accurate body composition analyzers, have been well established and utilized to measure the fluid status of the body, with more validity and operability compared to traditional evaluations of volume status $[19,20]$. In the process of measurement, there are 2 methods commonly adopted, including single-frequency BIA and multi-frequency BIA. It is of substantial interest to explore the effect of overhydration, as measured by BIA, on all-cause mortality and technique failure among PD patients. To our knowledge, this paper registers as the first attempt, via meta-analyses, to systematically investigate whether bioimpedance-assessed overhydration is an independent risk factor for mortality and technique failure in $\mathrm{PD}$ patients.

\section{Methods}

We conducted systematic review and meta-analyses by strictly complying with the Preferred Reporting Items for Systematic Reviews and Meta-analysis (PRISMA, shown in online suppl. Table S1; for all online suppl. material, see www.karger.com/ doi/10.1159/000492148) [21], a prevailing and rigorous guideline. Our analyses were based on de-identified data and published results, and neither ethics board review nor informed consent was required.

\section{Search Strategy}

Two reviewers (Y.S. and J.L.) searched PubMed/MEDLINE and OVID/EMBASE for observational studies published from 1974 to December 10, 2017 in English. The key words for searching these databases included "fluid status", "hydration status", "fluid overload", "over-hydration", "dehydration", "hypervolemia", "hypovolemia", "body water", "body composition analysis", "bioelectric impedance", "bioimpedance", and "PD", combined with "mortality", "survival" and "prognosis." Reviewers
(Y.S. and J.L.) also carefully read the references cited in the retrieved articles to find additional relevant studies. The final inclusion criteria were determined by the senior co-authors (X.Z. and P.F.). File S2 shows the details of the search strategy.

\section{Inclusion and Exclusion Criteria}

Primarily retrieved studies were independently screened by 2 reviewers (Y.S. and J.L.). Inclusion criteria were as follows: (i) observational cohort studies; (ii) adult patients diagnosed with end-stage renal disease and undergoing PD; and (iii) articles that reported the associations of fluid status with survival and prognostic outcomes of PD patients in terms of relative estimations, relative risk (RR) or hazard ratio (HR), accompanied by either $95 \% \mathrm{CI}$ or sufficient data to obtain these statistics. Meanwhile, studies were eliminated based on the following exclusion criteria: (i) abstracts, letters, editorials, experts' opinions, case reports and reviews; and (ii) studies where patients received renal replacement treatments other than PD.

\section{Data Extraction}

Data were extracted by 2 independent reviewers (Y.S. and J.L.) using a standardized form containing the first author's name and year of publication, locations where the studies were performed, mean age of participants at enrollment, number of patients, study designs, duration of follow-up, PD duration at enrollment, patient exclusion criteria, PD modality, dialysate status at measurement, the names of BIA devices, device and measurement details, overhydration criteria, RRs or HRs accompanied with 95\% CIs and corresponding control variables.

\section{Quality Assessment}

The quality of eligible studies was assessed using the NewcastleOttawa Quality Assessment Scale (NOS) for cohort [22] by 2 reviewers (Y.S. and J.L.) independently. A maximum of 9 points were distributed among 3 domains: selection (4 points), comparability ( 2 points), and exposure ( 3 points). Then, based on the obtained total NOS score, we rated a study quality as "High" (7-9 points), "Moderate" (4-6 points), or "Low" (0-3 points) [23].

\section{Data Synthesis and Analysis}

Stata V.13 (Stata Corporation, College Station, TX, USA) was used for the analysis. Two-sided $p$-values less than 0.05 were deemed statistically significant unless otherwise specified. The adjusted RRs with corresponding 95\% CIs were used as the effect size for all included studies, and HRs were treated as approximately equal to RRs [24-26].

We pooled the RRs concerning 2 outcomes (all-cause mortality and technique failure) to explore associations between hydration load and prognoses among patients undergoing PD using the Der Simonian and Laird [27] random effects model, which quantifies both within-study and between-study variations $[27,28]$. Of note, the pooled RRs were based on the dichotomized fluid status variable, which may have various cutoff values. Homogeneity across studies were tested by the Q statistic and quantitatively evaluated using the $I^{2}$ statistic. For the Q statistic, a significant heterogeneity was defined by a $p$ value $<0.10$. Values of $I^{2}$ below $30 \%$ were defined as unimportant, $30-50 \%$ as moderate, $50-75 \%$ as substantial, and $>75 \%$ as considerably heterogeneous [29].

To evaluate the stability of the results, especially for the pooled RRs with high heterogeneity, we conducted sensitivity analyses by 


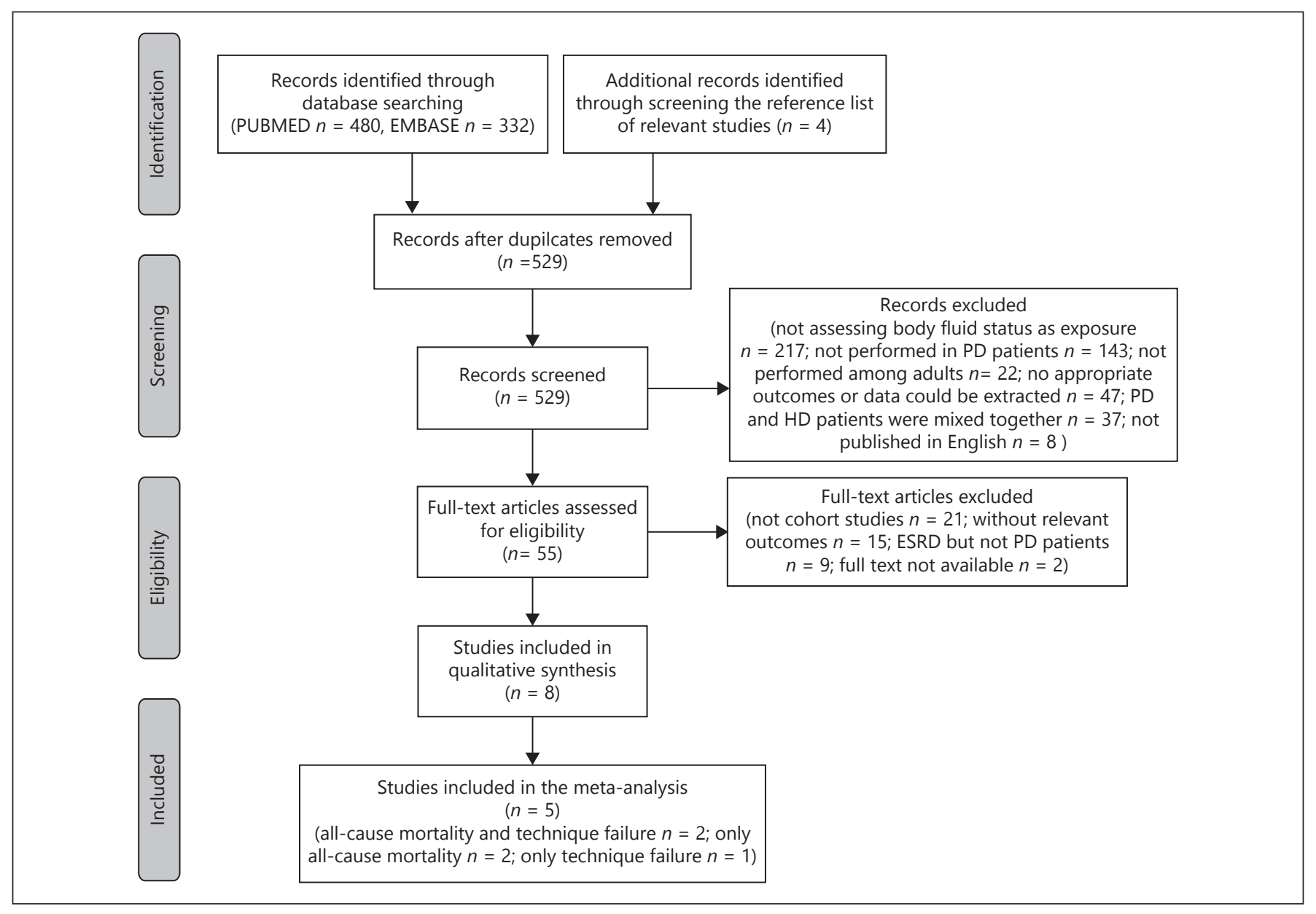

Fig. 1. The flow diagram of the study screening process.

obtaining pooled estimates in the absence of an individual study and by identifying sources of significant heterogeneities.

As only 8 articles were finally included, we did have insufficient data to perform subgroup analyses and publication bias tests since, in general, conducting such analyses requires the number of studies to be at least 10 [30]. Consequently, the funnel plots accompanied by the Egger's regression asymmetry test [31] and the Begg's adjusted rank correlation test [32] were not further considered.

\section{Results}

\section{Search Results}

Among the 529 unique studies identified from our search, 217 studies did not adopt fluid status related measurements as risk predictors, 165 studies did not involve adult PD patients, 47 studies did not provide qualified outcomes or sufficient data to compute them, 37 studies did not identify or extract PD patients, and 8 studies were not written in English. We further excluded 21 non-cohort studies, 15 studies without relevant outcomes, 9 studies with non-PD patients, and 2 studies without full text. We ended up with 8 eligible studies for systematic review; see Figure 1 for the PRISMA flow diagram of the screening process.

\section{Study Characteristics}

The characteristics of patients in the 8 included studies $[4,14,33-38]$, which consisted of a total of $1,989 \mathrm{PD}$ patients, are listed in Table 1 . There were 4 studies conducted in Asia (2 in China $[14,38]$, and 2 in Korea $[33,34])$, 3 studies in Europe (2 in the United Kingdom [4, 36], and 1 in Switzerland [35]), and 1 study in the United States [37]. The number of patients varied from 53 [37] to 631[34], and the mean follow-up time ranged from 1.0 year [34] to 7.5 years [33]. 


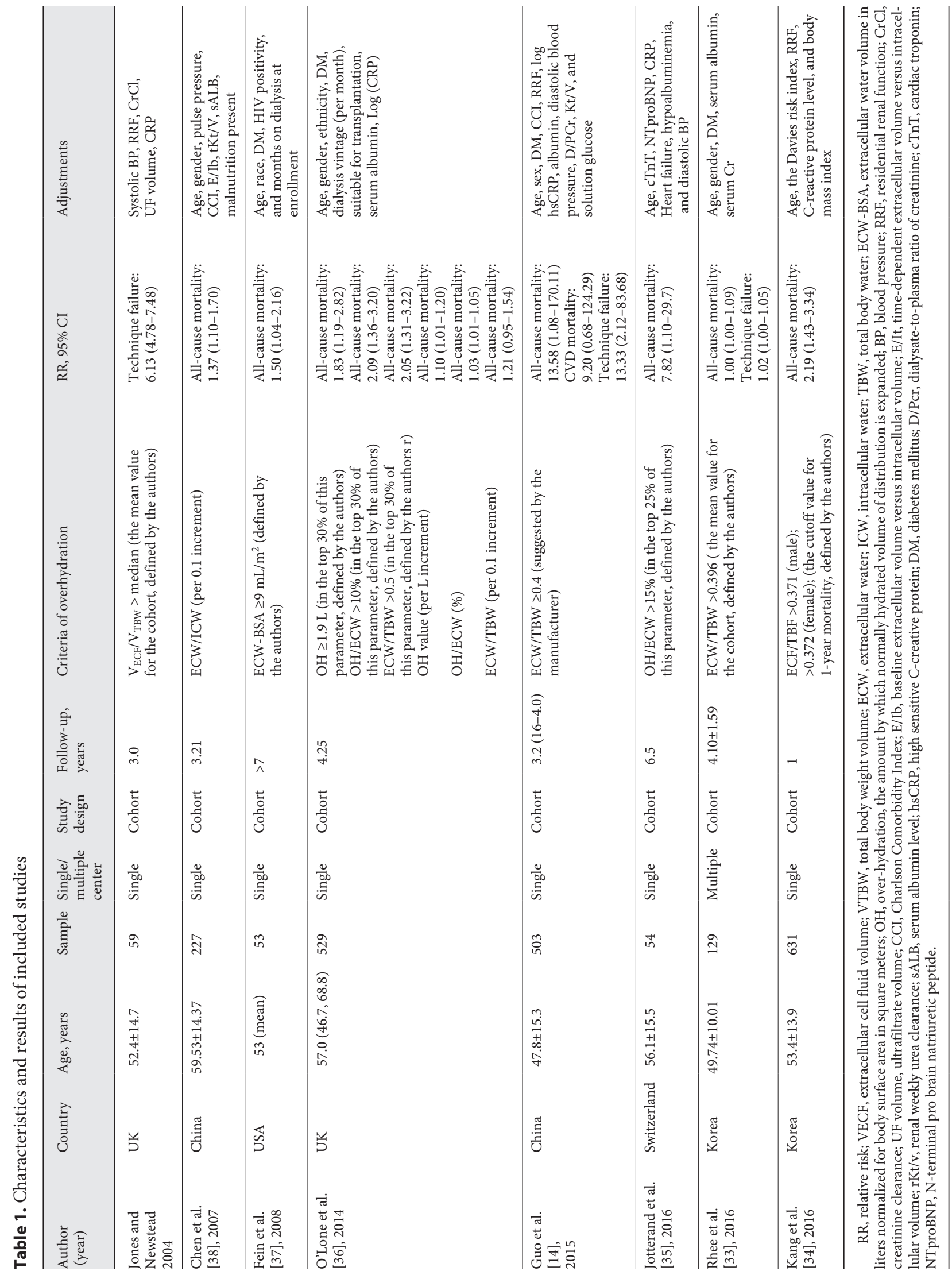


Table 2. Detailed information of bioimpedance devices and PD from included studies

\begin{tabular}{|c|c|c|c|c|c|}
\hline Author (year) & The names of devices & Device and measurement details & $\begin{array}{l}\text { PD duration } \\
\text { at Enrollment, } \\
\text { month }\end{array}$ & $\begin{array}{l}\text { PD modality } \\
\text { istribution }\end{array}$ & $\begin{array}{l}\text { Dialysate status } \\
\text { when performing } \\
\text { BIA }\end{array}$ \\
\hline $\begin{array}{l}\text { Fein et al. } \\
{[37], 2008}\end{array}$ & $\begin{array}{l}\text { Cyprus version } 1.0 \\
\text { (BIA-101: RJL/Akern Systems, } \\
\text { Clinton Township, MI, USA) }\end{array}$ & $\begin{array}{l}\text { Single-frequency BIA, } \\
800 \mathrm{~mA}, 50 \mathrm{kHz}\end{array}$ & NG & NG & NG \\
\hline $\begin{array}{l}\text { O'Lone et al. } \\
{[36], 2014}\end{array}$ & $\begin{array}{l}\text { The Body Composition } \\
\text { Monitor (BCM-Fresenius } \\
\text { Medical Care, } \\
\text { Bad Homburg, Germany) }\end{array}$ & $\begin{array}{l}\text { Multi-frequency BIA, } \\
50 \text { frequencies }(5-1,000 \mathrm{kHz}) \text {, paired } \\
\text { electrodes placed on wrist to ankle } \\
\text { on the one side of body }\end{array}$ & $5.1(0.8-32.1)$ & $\begin{array}{l}\text { CAPD + APD } \\
\text { (distribution: NG) }\end{array}$ & In situ \\
\hline $\begin{array}{l}\text { Jotterand } \\
\text { Drepper et al. } \\
{[35], 2016}\end{array}$ & $\begin{array}{l}\text { The Body Composition } \\
\text { Monitor (BCM-Fresenius } \\
\text { Medical Care, } \\
\text { Bad Homburg, Germany) }\end{array}$ & $\begin{array}{l}\text { Multi-frequency BIA, } \\
50 \text { frequencies }(5-1,000 \mathrm{kHz}) \text {, paired } \\
\text { electrodes placed on wrist to ankle } \\
\text { on the one side of body }\end{array}$ & $25.23 \pm 28.97$ & NG & In situ \\
\hline $\begin{array}{l}\text { Rhee et al. } \\
\text { [33], } 2016\end{array}$ & $\begin{array}{l}\text { InBody S20 body } \\
\text { composition analyzer } \\
\text { (Biospace, Seoul, Korea) }\end{array}$ & $\begin{array}{l}\text { Multi-frequency BIA, } \\
\text { NG }(1-1,000 \mathrm{kHz}) \\
\text { eight-point electrodes placed } \\
\text { on both hands and feet }\end{array}$ & $26.20 \pm 28.71$ & $\begin{array}{l}89.1 \% \text { CAPD } \\
+10.9 \% \text { APD }\end{array}$ & Empty \\
\hline $\begin{array}{l}\text { Kang et al. } \\
{[34], 2016}\end{array}$ & $\begin{array}{l}\text { InBody } 4.0 \text { Body } \\
\text { Composition Analyzer } \\
\text { (Biospace, Seoul, Korea) }\end{array}$ & $\begin{array}{l}\text { multi-frequency BIA, } \\
\text { NG, } \\
\text { eight-point electrodes placed } \\
\text { on both hands and feet }\end{array}$ & NG & $\begin{array}{l}84.2 \% \text { CAPD } \\
+15.8 \% \text { APD }\end{array}$ & Empty \\
\hline
\end{tabular}

PD, peritoneal dialysis; APD, automated peritoneal dialysis; CAPD, continuous ambulatory peritoneal dialysis; BIA, bioimpedance analysis; NG, not given.

Of these 8 studies, 7 studies reported all-cause mortality [14,33-38], 3 studies reported technique failure $[4,14$, 33], and one study reported cardiovascular mortality [14]. Patients' fluid statuses were all assessed by bioimpedance analyzers; 7 studies [4, 14, 33-36, 38] adopted multi-frequency BIA and only one study used single-frequency BIA [37]. Table 2 presents information on devices and measurement details.

Based on bioimpedance analyzers, several parameters were used to evaluate the hydration status. They included extracellular water/total body water (ECW/TBW), extracellular fluid/total body fluid (ECF/TBF), over-hydration index $(\mathrm{OH}), \mathrm{OH} / \mathrm{ECW}, \mathrm{ECW} /$ intracellular water (ICW), and ECW corrected by body surface area (BSA). To enumerate the body water composition, 3 studies $[14,33,36]$ adopted ECW/TBW, 1 study [34] adopted ECF/TBF, 1 study [4] used ECF volume $\left(\mathrm{V}_{\mathrm{ECF}}\right) / \mathrm{TBW}$ volume $\left(\mathrm{V}_{\mathrm{TBW}}\right)$, and 2 studies $[35,36]$ used OH/ECW. Still, the literature has not reached a consensus over hydration measurements, such as the BSA adjusted ECW (ECW-BSA [L/ $\mathrm{m}^{2}$ ]) [37], absolute value of $\mathrm{OH}$ (L) [36], or ECW/ICW [38]. The RRs of overhydration for all-cause mortality, technique failure or cardiovascular disease mortality were adjusted for in case of potential confounders, including age, gender, comorbidities, residual renal function, albumin, body mass index, high sensitive $\mathrm{C}$ reaction protein, blood pressure, dialysate-to-plasma ratio of creatinine, and urea clearance $\left(\mathrm{K}_{\mathrm{t}}\right)$ normalized to TBW $\left(\mathrm{K}_{\mathrm{t}} / \mathrm{V}_{\text {urea }}\right)$.

We conducted meta-analyses for both all-cause mortality and technique failure. Three studies $[14,33,36]$ adopted the ECW/TBW index and 1 study [34] used the ECF/ $\mathrm{TBF}$ as measures of overhydration exposure for risk of allcause mortality. Two studies adopted the ECW/TBW index $[14,33]$ and one study [4] used $\mathrm{V}_{\mathrm{ECF}} / \mathrm{V}_{\mathrm{TBW}}$ as an indi- 
Fig. 2. Pooled RR of all-cause mortality and technique failure.

\begin{tabular}{|c|c|c|c|}
\hline $\begin{array}{l}\text { Study } \\
\text { ID }\end{array}$ & & RR $(95 \% \mathrm{Cl})$ & $\begin{array}{l}\% \\
\text { Weight }\end{array}$ \\
\hline All-cause mortality-ECW/TBW & & & \\
\hline O'Lone EL, 2014 & $\rightarrow$ & $2.05(1.31,3.22)$ & 29.66 \\
\hline Guo Q, 2015 & & $13.58(1.08,170.11)$ & 5.20 \\
\hline Rhee H, 2016 & & $1.00(1.00,1.09)$ & 34.97 \\
\hline Kang SH, 2016 & • & $2.19(1.43,3.34)$ & 30.17 \\
\hline Subtotal $\left(R^{2}=88.7 \%, p=0.000\right)$ & & $1.08(0.96,3.36)$ & 100.00 \\
\hline Technique failure-ECW/TBW & & & \\
\hline Jones $\mathrm{CH}, 2004$ & 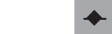 & $6.13(4.78,7.48)$ & 37.59 \\
\hline Guo Q, 2015 & & $13.33(2.12,83.68)$ & 24.52 \\
\hline Rhee H, 2016 & & $1.02(1.00,1.05)$ & 37.89 \\
\hline Subtotal $\left(R^{2}=99.2 \%, p=0.000\right)$ & & $3.76(0.81,17.42)$ & 100.00 \\
\hline Note: weights are from random effects analysis & & & \\
\hline 0.5 & 4 & 80170 & \\
\hline
\end{tabular}

cator of overhydration exposure for technique failure. We treated both $\mathrm{ECF} / \mathrm{TBF}$ and $\mathrm{V}_{\mathrm{ECF}} / \mathrm{V}_{\mathrm{TBW}}$ as equivalent measures of the ECW/TBW ratio for our statistical analysis, since the hydration status calculated by the ratio of ECF/ $\mathrm{TBF}$ and $\mathrm{V}_{\mathrm{ECF}} / \mathrm{V}_{\mathrm{TBW}}$ are highly correlated with water contents measured by the ECW/TBW ratio [37, 38, 43].

For quality assessment, 7 studies $[4,14,33-36,38]$ received "High" rankings (ranging from 7 to 8 points) and one study [37] was ranked "Fair" with a score of 5; please see online supplementary Table S3 for details.

\section{Results of All-Cause Mortality}

Three studies [14, 33, 36] adopting ECW/TBW and one study [34] adopting ECF/TBF as an overhydration indicator were included for the mortality meta-analysis. Pooled results indicated overhydration was responsible for an $80 \%$ higher, but non-significant, risk for all-cause mortality with considerable heterogeneity (RR 1.80, 95\% CI [0.96-3.36]; $p=0.067 ; I^{2}=88.7 \%, p<0.001$; Forest plots are shown in Fig. 2).

Meanwhile, 4 studies used less popular overhydration indicators. Two studies identified $\mathrm{OH} / \mathrm{ECW}$ as an independent risk factor for all-cause mortality, but they used various cutoffs and reached different results. Specifically, with $\mathrm{OH} / \mathrm{ECW}>10 \%$ [36], the RR is 2.09 with $95 \% \mathrm{CI}$ (1.36-3.20), and with $\mathrm{OH} / \mathrm{ECW}>15 \%$ (1), the RR is 7.82 with 95\% CI (1.10-29.7). Two other studies discovered that ECW-BSA $\geq 9 \mathrm{~mL} / \mathrm{m}^{2}$ (RR 1.50, 95\% CI [1.04-2.16]; $p=0.03$ ) [37] and $\mathrm{OH} \geq 1.9 \mathrm{~L}$ (RR $1.83,95 \%$ CI [1.192.82]; $p=0.006)$ [36] are significant risk factors for allcause mortality among $\mathrm{PD}$ patients.

Overhydration and Prognosis in PD

Patients
A few studies also reported the continuous versions of the overhydration measurements. We found that several are significantly associated with all-cause mortality: ECW/ ICW (per increment of 10\%; RR 1.37, 95\% CI [1.10-1.70]; $p=0.005)$ [38], OH (per increment of liter) (RR 1.10, 95\% CI [1.01-1.20]; $p=0.029$ ) [36], and OH/ECW (per increment of 10\%; RR 1.03, 95\% CI [1.01-1.05]; $p=0.003)$ [36], though not ECW/TBW (per increment of $10 \%$; RR $=1.21$, 95\% CI [0.95-1.54]; $p=0.123$ ) [36]. Finally, Guo et al. [14] found that the PD patients with ECW/TBW $\geq 0.4$ encountered a higher but non-significant risk of cardiovascular disease death compared to the group with ECW/TBW $<0.4$ (RR 9.2, 95\%CI [0.68-124.29]; $p=0.094$ ).

\section{Results of Technique Failure}

All 3 studies $[4,14,33]$ on the association between overhydration (defined by a higher ratio of ECW/TBW) and technique failure led to a nonsignificant pooled estimate with considerable heterogeneity (RR 3.76, 95\% CI [0.81-17.42], $p=0.09 ; I^{2}=99.2 \%, p<0.001$ ) (Forest plots are shown in Fig. 2). No included studies used continuous hydration variables to explore their association with technique failure.

\section{Results of Sensitivity Analyses}

The study from Rhee et al. [33], the only multicenter study among our included studies, was a major source of heterogeneity in our analyses. After removing it [33], both pooled RRs for all-cause mortality and technique failure risk reached a statistical significant level with greatly reduced heterogeneity (all-cause mortality: RR 
Fig. 3. Pooled RR of all-cause mortality and technique failure in sensitive analysis.

\begin{tabular}{|c|c|c|c|}
\hline $\begin{array}{l}\text { Study } \\
\text { ID }\end{array}$ & & RR $(95 \% \mathrm{Cl})$ & $\begin{array}{l}\% \\
\text { Weight }\end{array}$ \\
\hline \multicolumn{4}{|l|}{ All-cause mortality-ECW/TBW } \\
\hline O'Lone EL, 2014 & $\leadsto$ & $2.05(1.31,3.22)$ & 46.55 \\
\hline Guo Q, 2015 & & $13.58(1.08,170.11)$ & 1.57 \\
\hline Kang SH, 2016 & $\rightarrow$ & $2.19(1.43,3.34)$ & 51.88 \\
\hline Subtotal $\left(R^{2}=3.9 \%, p=0.353\right)$ & $\diamond$ & $2.19(1.59,3.00)$ & 100.00 \\
\hline \multicolumn{4}{|l|}{ Technique failure-ECW/TBW } \\
\hline Jones $\mathrm{CH}, 2004$ & 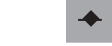 & $6.13(4.78,7.48)$ & 98.54 \\
\hline Guo Q, 2015 & & $13.33(2.12,83.68)$ & 1.46 \\
\hline Subtotal $\left(R^{2}=0.0 \%, p=0.411\right)$ & $\diamond$ & $6.20(4.96,7.74)$ & 100.00 \\
\hline \multicolumn{4}{|l|}{ Note: weights are from random effects analysis } \\
\hline 0.51 & 4 & 80170 & \\
\hline
\end{tabular}

$2.19,95 \%$ CI [1.59-3.00], $p<0.001 ; I^{2}=3.9 \%, p=0.353$. Technique failure: RR 6.20, 95\% CI [4.96-7.74], $p<0.001$; $I^{2}=0.0 \%, p=0.411$; Forest plots are shown in Fig. 3 ).

\section{Discussion}

Our meta-analyses have revealed that overhydration, defined by a higher ratio of ECW/TBW, significantly increases the risk of both all-cause mortality and technique failure among PD patients. The pooled RRs of the higher ratios of ECW/TBW for all-cause mortality and technique failure were nonsignificant with large heterogeneity caused by one study that consisted of multicenter and small-scale cohorts [33]. However, after removing this study [33], the pooled results were significant with greatly reduced heterogeneity. Meanwhile, we also identified significant associations between other hydration indices (such as $\mathrm{OH} / \mathrm{ECW}$, ECW-BSA, OH, and ECW/ICW) and all-cause mortality.

Of note, there were various indices used to evaluate hydration status when using bioimpedance devices to measure. The ECW/TBW ratio was most frequently used, whereas $\mathrm{OH} / \mathrm{ECW}, \mathrm{ECW}-\mathrm{BSA}, \mathrm{OH}$, and ECW/ICW were less frequently adopted. ECW/TBW ratios obtained from different devices among the same patients were well consistent, although the absolute values of ECW and TBW were different [39], thus leading to the wide use of ECW/TBW. However, the ECW/TBW ratio might be affected by body cell mass and nutritional state [39, 40]. And it is known that ECW/TBW depends on obesity, age, gender, and ethnicity $[40,41]$. Therefore, these confounding factors should be adjusted to minimize bias. Concerning our 5 included studies $[4,14,33,34,36]$ for meta- analysis, confounders related to those mentioned above were adjusted, and thus pooled outcomes based on ECW/ TBW might be more reliable.

Meanwhile, a significant effect from overhydration on all-cause mortality could be found when using less used indices. Although the cutoff values of OH/ECW were a little different to define the relative overhydration, all the results indicating an association between overhydration and all-cause mortality were significant. In addition, other hydration indices (including ECW-BSA, OH, and ECW/ICW), though from one study, demonstrated significant relationships between overhydration and allcause mortality.

To characterize overhydration measurements with higher quality, important confounders might be carefully considered. Firstly, outcome could be affected by the time point (incident or prevalent), frequency of electrical current, body position, and electrode placement when performing hydration measurements. Second, results from patients undergoing continuous ambulatory PD or automated PD might be different, which needed to be confirmed by further subgroup analyses, however ended up with insufficient data. Furthermore, it is controversial whether dialysate remained in situ could impose effect on the measurement value. Davenport et al. [42] reported that dialysate in situ might overestimate ECW and consequently ECW/TBW. But this conclusion was contradicted with speculation that whole-body bioimpedance spectroscopy does not measure sequestered fluid in the trunk, and it was further strengthened by results from Davison et al. [43].

We initially performed this systematic review to investigate associations between PD outcomes (including pa- 
tients' all-cause mortality and technique failure) and fluid status (including both overhydration and dehydration) based on BIA. However, there were few studies reporting the RR of dehydration. For some studies, the continuous versions of hydration status were also considered to further quantify its association with the outcomes.

We note that our systematic review and meta-analysis have some limitations. First, given the limited number of studies included (8 studies), which were mostly singlecenter and retrospective studies, and the varying sample sizes (from 53 to 631), the patients of the included studies may not well represent the overall population. Having more data from the regions where $\mathrm{PD}$ prevalence rates are high, such as Hong Kong, Taiwan, Japan, New Zealand, and mainland China [44], would strengthen the conclusion. Second, identical criteria were not applied between studies in classifying overhydration, which limited further meta-analyses and subgroup analyses for each same hydration indicator.

\section{Conclusions}

Overhydration, defined by a higher ratio of ECW/ TBW, might be an independent predictor for both allcause mortality and technique failure among PD patients.
Multicenter prospective cohort studies from more representative areas and countries, with identical criteria of overhydraion, unified measurement strategies and suitable bioimpedance devices, are warranted to further confirm this conclusion.

\section{Acknowledgments}

We thank Martina Fu, our technical editor, for proofreading the article and for many helpful suggestions that significantly improved the quality and presentation of the paper.

\section{Financial Disclosure}

This work received grants from Science and Technology Department of Sichuan Province, China (2016HH0069), and Chengdu Science and Technology Bureau (2015-RK00-00252-ZF). The sponsors played no roles in study design, data collection and analysis, decision to publish, or preparation of the manuscript. There was no additional funding received for this study.

\section{Disclosure Statement}

Authors declare that they have no conflicts of interest to disclose.

\section{References}

1 Tian Y, Xie X, Xiang S, Yang X, Zhang X, Shou Z, Chen J: Risk factors and outcomes of high peritonitis rate in continuous ambulatory peritoneal dialysis patients: a retrospective study. Medicine 2016;95:e5569.

2 Rocha A, Rodrigues A, Teixeira L, Carvalho MJ, Mendonca D, Cabrita A: Temporal trends in peritonitis rates, microbiology and outcomes: the major clinical complication of peritoneal dialysis. Blood Purif 2012;33:284-291.

3 Blake PG, Flowerdew G, Blake RM, Oreopoulos DG: Serum albumin in patients on continuous ambulatory peritoneal dialysis-predictors and correlations with outcomes. J Am Soc Nephrol 1993;3:1501-1507.

4 Jones CH, Newstead CG: The ratio of extracellular fluid to total body water and technique survival in peritoneal dialysis patients. Perit Dial Int 2004;24:353-358.

5 Annual mortality rates: CAPD/CCPD patients. https://www.usrds.org/2015/view/Default.aspx. Volume 2 - End-stage Renal Disease (ESRD) in the United States. Incidence, Prevalence, Patient Characteristics, and Treatment Modalities (accessed March 15, 2017).

6 Ronco C, Verger C, Crepaldi C, Pham J, De Los Rios T, Gauly A, Wabel P, Van Biesen W:
Baseline hydration status in incident peritoneal dialysis patients: the initiative of patient outcomes in dialysis (IPOD-PD study) $\dagger$. Nephrol Dial Transplant 2015;30:849-858.

7 Guo Q, Yi C, Li J, Wu X, Yang X, Yu X: Prevalence and risk factors of fluid overload in Southern Chinese continuous ambulatory peritoneal dialysis patients. PLoS One 2013; 8:e53294.

8 Kwan BC, Szeto CC, Chow KM, Law MC, Cheng MS, Leung CB, Pang WF, Kwong VW, Li PK: Bioimpedance spectroscopy for the detection of fluid overload in Chinese peritoneal dialysis patients. Perit Dial Int 2014;34: 409-416.

9 Kazory A: Fluid overload as a major target in management of cardiorenal syndrome: implications for the practice of peritoneal dialysis. World J Nephrol 2017;6:168-175.

10 Hyun SH, Choi JY, Cho JH, Park SH, Kim CD, Kim YL: Assessment of fluid and nutritional status using multifrequency bioelectrical impedance analysis in peritoneal dialysis patients. Blood Purif 2014;37:152-162.

11 Kim YL, Biesen WV: Fluid overload in peritoneal dialysis patients. Semin Nephrol 2017; $37: 43-53$.
12 Paniagua R, Ventura MD, Avila-Diaz M, Hinojosa-Heredia H, Mendez-Duran A, CuetoManzano A, Cisneros A, Ramos A, MadoniaJuseino C, Belio-Caro F, Garcia-Contreras F, Trinidad-Ramos P, Vazquez R, Ilabaca B, Alcantara G, Amato D: NT-proBNP, fluid volume overload and dialysis modality are independent predictors of mortality in ESRD patients. Nephrol Dial Transplant 2010;25:551-557.

13 Hogas S, Ardeleanu S, Segall L, Serban DN, Serban IL, Hogas M, Apetrii M, Onofriescu M, Sascau R, Covic A: Changes in arterial stiffness following dialysis in relation to overhydration and to endothelial function. Int Urol Nephrol 2012;44:897-905.

14 Guo Q, Lin J, Li J, Yi C, Mao H, Yang X, Yu $\mathrm{X}$ : The effect of fluid overload on clinical outcome in Southern Chinese patients undergoing continuous ambulatory peritoneal dialysis. Perit Dial Int 2015;35:691-702.

15 Demirci MS, Demirci C, Ozdogan O, Kircelli F, Akcicek F, Basci A, Ok E, Ozkahya M: Relations between malnutrition-inflammationatherosclerosis and volume status. The usefulness of bioimpedance analysis in peritoneal dialysis patients. Nephrol Dial Transplant 2011;26:1708-1716. 
16 Cheng LT, Tang W, Wang T: Strong association between volume status and nutritional status in peritoneal dialysis patients. Am J Kidney Dis 2005;45:891-902.

17 Konings CJ, Kooman JP, Schonck M, Struijk DG, Gladziwa U, Hoorntje SJ, van der Wall Bake AW, van der Sande FM, Leunissen KM: Fluid status in CAPD patients is related to peritoneal transport and residual renal function: evidence from a longitudinal study. Nephrol Dial Transplant 2003;18:797-803.

18 Kalantar-Zadeh K, Ikizler TA, Block G, Avram MM, Kopple JD: Malnutrition-inflammation complex syndrome in dialysis patients: causes and consequences. Am J Kidney Dis 2003;42:864-881.

19 Dell'Aquila R, Rodighiero MP, Di Loreto P, Spano E, Brendolan S, Crepaldi C, Nalesso F, Corradi V, De Cal M, Bragano P, Ronco C: A new home based bioimpedance system for PD. Contrib Nephrol 2006;150:326-335.

20 Oei EL, Fan SL: Practical aspects of volume control in chronic kidney disease using whole body bioimpedance. Blood Purif 2015;39:3236.

21 Moher D, Liberati A, Tetzlaff J, Altman DG: Preferred reporting items for systematic reviews and meta-analyses: the PRISMA statement. Ann Intern Med 2009;151:264-269, w264.

22 Rostom A,Dube C,Cranney A, et al. Celiac Disease. Rockville(MD): Agency for Healthcare Research and Quality (US); 2004 Sep. (Evidence Reports/Technology Assessments, No. 1 04.) Appendix D. Quality Assessment Forms.http://www.ncbi.nlm.nih.gov/books/ NBK35156.

23 Liu J, Zeng X, Hong HG, Li Y, Fu P: The association between body mass index and mortality among Asian peritoneal dialysis patients: a meta-analysis. PLoS One 2017;12:e0172369.

24 Shao C, Tang H, Zhao W, He J: Nut intake and stroke risk: a dose-response meta-analysis of prospective cohort studies. Sci Rep 2016;6: 30394.

25 Grosso G, Yang J, Marventano S, Micek A, Galvano F, Kales SN: Nut consumption on all-cause, cardiovascular, and cancer mortality risk: a systematic review and meta-analysis of epidemiologic studies. Am J Clin Nutr 2015;101:783-793.

26 Afshin A, Micha R, Khatibzadeh S, Mozaffarian $\mathrm{D}$ : Consumption of nuts and legumes and risk of incident ischemic heart disease, stroke, and diabetes: a systematic review and meta-analysis. Am J Clin Nutr 2014;100: 278-288.

27 DerSimonian R, Laird N: Meta-analysis in clinical trials. Control Clin Trials 1986;7:177188.

28 DerSimonian R, Laird N: Meta-analysis in clinical trials revisited. Contemp Clin Trials 2015;45:139-145.

29 Higgins JP, Thompson SG, Deeks JJ, Altman DG: Measuring inconsistency in meta-analyses. BMJ 2003;327:557-560.

30 Mavridis D, Salanti G: How to assess publication bias: funnel plot, trim-and-fill method and selection models. Evid Based Ment Health 2014;17:30.

31 Egger M, Davey Smith G, Schneider M, Minder C: Bias in meta-analysis detected by a simple, graphical test. BMJ 1997;315:629-634.

32 Begg CB, Mazumdar M: Operating characteristics of a rank correlation test for publication bias. Biometrics 1994;50:1088-1101.

33 Rhee H, Baek MJ, Chung HC, Park JM, Jung WJ, Park SM, Lee JW, Shin MJ, Kim IY, Song SH, Lee DW, Lee SB, Kwak IS, Seong EY: Extracellular volume expansion and the preservation of residual renal function in Korean peritoneal dialysis patients: a long-term follow up study. Clin Exp Nephrol 2016;20:778786.

34 Kang SH, Choi EW, Park JW, Cho KH, Do JY: Clinical significance of the Edema index in incident peritoneal dialysis patients. PLoS One 2016;11:e0147070.

35 Jotterand Drepper V, Kihm LP, Kalble F, Diekmann C, Seckinger J, Sommerer C, Zeier $\mathrm{M}$, Schwenger V: Overhydration is a strong predictor of mortality in peritoneal dialysis patients - independently of cardiac failure. PLoS One 2016;11:e0158741.
36 O'Lone EL, Visser A, Finney H, Fan SL: Clinical significance of multi-frequency bioimpedance spectroscopy in peritoneal dialysis patients: independent predictor of patient survival. Nephrol Dial Transplant 2014;29: 1430-1437.

37 Fein P, Chattopadhyay J, Paluch MM, Borawski C, Matza B, Avram MM: Enrollment fluid status is independently associated with long-term survival of peritoneal dialysis patients. Adv Perit Dial 2008;24:79-83.

38 Chen W, Guo LJ, Wang T: Extracellular water/intracellular water is a strong predictor of patient survival in incident peritoneal dialysis patients. Blood Purif 2007;25:260-266.

39 Davies SJ, Davenport A: The role of bioimpedance and biomarkers in helping to aid clinical decision-making of volume assessments in dialysis patients. Kidney Int 2014;86: 489-496.

40 Chamney PW, Wabel P, Moissl UM, Muller MJ, Bosy-Westphal A, Korth O, Fuller NJ: A whole-body model to distinguish excess fluid from the hydration of major body tissues. Am J Clin Nutr 2007;85:80-89.

41 Moissl UM, Wabel P, Chamney PW, Bosaeus I, Levin NW, Bosy-Westphal A, Korth O, Muller MJ, Ellegard L, Malmros V, Kaitwatcharachai C, Kuhlmann MK, Zhu F, Fuller NJ: Body fluid volume determination via body composition spectroscopy in health and disease. Physiol Meas 2006;27:921-933.

42 Davenport A: Does peritoneal dialysate affect body composition assessments using multifrequency bioimpedance in peritoneal dialysis patients? Eur J Clin Nutr 2013;67:223-225.

43 Davison SN, Jhangri GS, Jindal K, Pannu N: Comparison of volume overload with cyclerassisted versus continuous ambulatory peritoneal dialysis. Clin J Am Soc Nephrol 2009; 4:1044-1050.

44 Li PK, Chow KM, Van de Luijtgaarden MW, Johnson DW, Jager KJ, Mehrotra R, Naicker S, Pecoits-Filho R, Yu XQ, Lameire N: Changes in the worldwide epidemiology of peritoneal dialysis. Nat Rev Nephrol 2017;13:90103. 